\title{
Aging in America: Ageism and General Attitudes toward Growing Old and the Elderly
}

\author{
Raqota Berger \\ California State University, Northridge, USA \\ Email:rberger@vcccd.edu
}

How to cite this paper: Berger, R. (2017) Aging in America: Ageism and General Attitudes toward Growing Old and the Elderly. Open Journal of Social Sciences, 5, 183-198.

https://doi.org/10.4236/jss.2017.58015

Received: July 29, 2017

Accepted: August 12, 2017

Published: August 15, 2017

Copyright $\odot 2017$ by author and Scientific Research Publishing Inc. This work is licensed under the Creative Commons Attribution International License (CC BY 4.0).

http://creativecommons.org/licenses/by/4.0/ (c) (i) Open Access

\begin{abstract}
Ageism is the one form of social prejudice that people from all social backgrounds have to deal with. We live in a world where youth is valued over old age and where old people are often mistreated and negatively stereotyped. Major social institutions are largely behind these negative attitudes toward the elderly, particularly the mass media. The current study examined people's attitudes and feelings about the elderly and about growing old. Survey data were collected on 154 respondents living in Southern California. Respondents provided information on their feelings and attitudes about the elderly and about how society views and treats the elderly. Respondents also provided information about their feelings, attitudes, and fears about growing old themselves. The data revealed that there is a general sense of ambivalence about the elderly and about growing old. Although the findings were mixed, young people appear to have more negative feelings in general and there appears to be a greater concern among women about growing old. Native Americans and Middle Eastern respondents had the most favorable views about the elderly. The findings of the study support the position that ageism is still a social problem and that most people have somewhat mixed feelings about the elderly and about growing old. Future research should look further at how the mass media and larger cultural stereotypes and attitudes affect the lives, functioning, and treatment of our eldest members of society.
\end{abstract}

\section{Keywords}

Ageism, Attitudes toward the Elderly, Fear of Aging, Mass Media

\section{Introduction}

America is well known for its obsession with youth. Youth and beauty are glorified across all forms of media and we are taught from a very young age that "new 
things" are the best. People fixate on trying to look much younger that they are. Plastic surgery for both men and women is at an all-time high. Most forms of plastic surgery are elective and have more to do with vanity and physical appearance than anything else. Hollywood movies typically only cast young women in leading roles, and leading men are typically strong, fit, and virile. Fashion magazines marketed to women only put young, beautiful, and thin women on their covers. Men's magazines pretty much do the same, but with male models, actors, and famous athletes. What are the messages being sent? What does this do to our sense of self, our self-esteem, and our attitudes toward aging? How does this shape our views toward the elderly, and our own concerns about getting old?

Even though the United States has an aging population there is still a clear bias against aging and a general fear of getting old. Even though the emphasis on youth and beauty has traditionally been directed more toward females than males, we are now seeing an increasing concern with males about aging and getting old. The elderly used to be a highly respected group and were admired for their experience and wisdom. Changes in the political, social, and economic landscape altered perceptions about aging and ultimately decreased the status and position of the elderly in society [1]. With a growing sense of individualism and an increasing concern with staying young, older people have had to face an escalating level of disregard, disrespect, and marginalization. These prevailing social and cultural issues have indubitable social and academic significance that merits far more attention and applied action than it is now receiving.

At the center of this marginalization and devaluing of the elderly is the mass media. The mass media has largely become the central nervous system of American society and has a massive impact on people's values, beliefs, and perceptions [2]. This has been demonstrated endlessly across research in the social and behavioral sciences and the overall belief is that portrayals of the elderly are largely negative and stereotypical. Common feelings toward the elderly are that they are of low status and incompetent [3] and this is a common theme running across media representations. The elderly are often depicted as weak, unattractive, and senile. Other cultural stereotypes often seen in the media portray the elderly as frail, feeble, financially distressed, and not contributing to society [4].

If American society moves further in the direction of secularism, materialism, and individualism, we can expect to see these negative attitudes and perceptions toward the elderly, and aging in general, to continue. As long as our primary social institutions, such as the mass media, continue to represent old age as something to be feared and avoided then we can expect to see harmful stereotypes and a general prejudice toward our oldest members of society to continue. This study set out to uncover how people feel about the elderly and what their attitudes are toward aging itself. It is hoped that the more this topic is studied and addressed the more we can work to reduce the negative treatment and marginalization of the elderly in society. Promoting positive attitudes toward aging would also help people to embrace their own lifelong development and to not fear losing their 
youth. Old age is not something to be feared and disrespected. Ageism is a significant social problem. Researchers and academics need to place more emphasis on this larger cultural problem and try to figure out ways to minimize its impact on our aging population. In America, the fastest growing segment of the population is those 65 years of age and older. The baby boomers are now among the ranks of the elderly. It is going to be necessary to try and change the culture and people's general attitudes about aging and the elderly. Ageism has real implications on people's lives and overall functioning. This paper will explore these issues further and present original findings on the topic.

\section{Literature Review}

The United States population of those 65 years of age and older is estimated to double from 2000 to 2030 [5]. This growing population trend is going to bring with it an increased importance in public policy regarding health services, community services, and larger institutional practices. Some of the most important issues that will need to be better addressed concern cultural and attitudinal prejudice and discrimination against the elderly. Examples of this include discrimination in the workplace and media bias that promotes negative attitudes toward the elderly [6]. Thornton (2002) put forth a number of common cultural stereotypes that serve to isolate and devalue the elderly, such as the elderly being senile, of poor health, lacking vitality, unproductive, sexless, depressed, and unwilling to learn and change [7]. These labels only serve to institutionalize prejudice against the elderly and further promote the poor treatment of this particular social group. In their study on children's views of older people, Howatson and Jones (2014) found that although children are less discriminatory overall, they still adopt cultural stereotypes about the elderly that shapes their views and developing attitudes toward them. They also found that these negative effects can be mediated by better quality of contact and familiarity with the elderly [1]. The evidence seems to indicate that ageism does not exist in very young people. Ageism appears to be a learned phenomenon through exposure to larger cultural and societal biases and prejudices.

There is a widespread belief that the mass media is a central producer of prejudice and bias against the elderly. Common portrayals often show the elderly as being sad, depressed, senile, wrinkled, unattractive, and dependent [4] [8] [9]. Research has consistently shown that by the time people reach their college years they have already developed a deeply ingrained perspective on the elderly and have internalized dominant cultural assumptions about the elderly. Cuddy, Norton, and Fiske (2005) conducted a study at Princeton University and found that the students by and large clung to common stereotypes about the elderly, most notably those pertaining to the elderly being incompetent and less ambitious. Although their findings were mixed in regard to general discrimination and prejudice toward the elderly (e.g., both positive and negative feelings were present), they found that although most students felt a sense of warmth toward the elderly the most common sentiment involved feelings of pity toward them 
[3].

Other researchers have also found mixed results regarding attitudes toward the elderly. Lin and Bryant (2009) found that students in Western cultures such as the United States seem to have a certain level of ambivalence about the elderly and aging. They found that students tend to hold both positive and negative attitudes and feelings that seem to be in line with what other research has found (e.g., the elderly are warm, but incompetent) [10]. These findings seem to hold across other nations as well. As an example, McKenzie and Brown (2014) conducted a study with 135 nursing students in Australia (aged 18 to 55) and found that they held a generally negative attitude toward working with the elderly and were somewhat prejudiced against them. This was believed to be associated with terror management theory in which people try to distance themselves from older people because of their own fear of death [11]. A study with 491 Israeli students also had similar findings and concluded that students have a general negative attitude toward the elderly. The researchers used the Frabroni Scale of Ageism (FSA) and concluded that students hold typical prejudicial attitudes toward the elderly and typically engage in behavioral avoidance [12].

Interestingly, a number of studies have found that students attitudes toward the elderly is generally less positive (and more negative) in Asian societies. In their study on ageism in Asian and Western cultures, Vauclair, Hanke, Huang, and Abrams (2017) found that Taiwanese students generally held more negative perceptions and attitudes toward the elderly than students in the United Kingdom [13]. Another study with 44 Thai students and 44 American students concluded that the Thai students held more negative attitudes about elders. The researchers used an adjective-generation task and a mixed-design analysis and found that gerontocratic traditions do not insulate against negative stereotyping and ageist feelings toward the elderly [14]. A study with 980 Chinese students found that collectivism and filial piety do not buffer against negative attitudes and stereotypes against the elderly [15]. The researchers discovered through their work that there is a positive association between high interaction and more positive attitudes toward older individuals. With this stated, they also concluded that economic stress, certain legal responsibilities, and the burden of caregiving, causes young individuals to be somewhat resentful and negative toward the elderly. These types of findings seem to hold across a number of studies [6] [10] [16] and appears to contradict what many scholars have put forth about attitudes and beliefs between individualistic cultures versus collectivistic cultures in regard to the elderly [10] [12] [13] [17]. North and Fiske (2015) described how even though Asian cultures are more collectivistic than Western cultures, and that they have a long tradition of filial piety, attitudes in the East are more negative overall. They explained this through a larger historical perspective that looked at issues with cultural tolerance, industrialization, conflict over resources, and overall contact (the contact hypothesis) and found that although Western societies also hold mixed attitudes toward their elderly members, those in the East seem to have a more negative disposition toward their elderly members 
[18].

Although the research to date seem to present mixed findings about people's general attitudes toward the elderly there does seem to be a consistency in certain areas. The research does show that both Western and Eastern societies generally place more value on youth than on old age [3] [12] [19], that people generally believe that older people are less competent and more of a drain on resources [3] [5] [15], and older women are generally viewed more negatively than men [8] [16] [20] [21]. This last point is interesting because there appears to be a strong feeling that older males are viewed more favorably than older females (e.g., less dependent, more autonomous, more competent, mores self-reliant), and women appear to be viewed as less attractive, less productive, and less intelligent [19] [20] [21]. It is widely believed that traditional belief systems and contemporary media play into these negative and harmful beliefs.

According to Robinson, Gustafson, and Popovich (2008), most advertisements featuring older individuals contain harmful stereotypical images and messages and this affects how older people feel about themselves and how young people view the elderly [1]. This is also supported by other researchers that have found that the media perpetuates harmful stereotypes and promotes negative attitudes toward the elderly [4] [19]. There appears to be a fear of aging in society that causes people to experience a sense of negativity toward the elderly and a general sense of anxiety about getting older [6]. This fear of aging manifests itself in many different ways, including prejudicial attitudes and even discrimination toward the elderly. Nelson (2005) suggests that this fear of aging is a socially condoned prejudice that strips the elderly of power and dignity. It is through the use of patronizing language, along with a general negative disposition toward the elderly (e.g., as being burdens on society), that is at the heart of this larger social problem [5].

In sum, as can be seen from the range of studies that have been done on the topic of aging and ageism, there is a strong consensus that people generally favor youth over old age and that people often have mixed feelings about the elderly. Research across various nations and cultures has also shown that these feelings are not as clear as once thought. People from Western nations do not have a uniformly negative attitude toward the elderly, just as those from the East do not have a universally positive attitude toward the elderly. The literature seems to suggest a more mixed sentiment that is more complex than any simple explanation can provide. Larger cultural forces, such as the economy, the mass media, and the political climate also play a major role in all of this. The literature also makes it clear that ageism and negative attitudes toward the elderly is a fact a fact of life and is a real social problem that merits further attention.

\section{Purpose of Research and General Hypotheses}

The goal of this study is to illuminate people's feelings about old age, as well as people's attitudes toward the elderly in general. The purpose is to get a better sense of which social groups may have the most negative attitudes toward the 
elderly and which social groups may have the most concern or fear about growing old in American society (e.g., gender, ethnicity). Some basic propositions put forth in this study is that females will demonstrate more of a concern about growing old than males, young people will fear growing old more than middle-aged adults or adults that are already considered to be among the elderly, and that a significant percentage of respondents will show at least some ambivalence toward growing older and toward the elderly. Put succinctly: Females will show more ambivalence or concern about growing old than males. Younger people will show more ambivalence or concern about being old than older adults. The respondents will generally have ambivalence about getting old and will generally have less than positive attitudes about the elderly. The research also set out to detect any notable differences between ethnic groups. Prior research has shown that some ethnic groups tend to have more ambivalent attitudes towards the elderly than other ethnic groups.

The general purpose of the research is to lend support to the standing literature that has consistently demonstrated that Americans generally have a less than positive attitude toward the elderly and toward growing old. The study was also designed to highlight some of the top concerns that people have about getting old and to make associations across various social groups and their attitudes toward aging and the elderly. Another goal was to look beyond what respondents directly say and what their responses actually reveal. It is often the case that respondents will give answers that do not always truthfully reflect what they really feel, especially when it may be considered unpopular or politically incorrect. A goal of this work is to be able to look beyond mere description and make valid inferences about people's general attitudes and dispositions toward the elderly and about getting old. The final purpose is to make analytic connections between what has been found in prior research on this topic and on related topics, to bring forth commonly held attitudes and feelings toward the elderly, and to make concluding statements and inferences about common concerns, prejudices, and ageism in general.

It is hypothesized that young people will generally demonstrate a more negative attitude toward the elderly and toward aging in general than older people. It is predicted that relatively young respondents will also show a greater fear of aging than the older respondents. It is also being hypothesized that feelings toward the elderly will not be uniformly negative and universally the same across all social groups (e.g., gender and ethnicity). It is believed that most people will show mixed feelings and attitudes toward the elderly and toward aging in general. With this, it is also believed that there will be a general favorability toward being young over being old across all social groups that participate in the study.

\section{Research Methodology}

\subsection{Research Design}

The study used a quantitative survey to collect data (see Appendix). The survey 
consisted of several questions asking about basic demographic variables (e.g., gender, ethnicity, age). These variables are important for making comparisons across social groups and for making any inferences about group differences. The survey also consisted of 9 Likert-type scale items designed to provide information about general attitudes, feelings, and concerns about the elderly and about growing old. The scales range from 1 to 5 , where 1 meant "Strongly Disagree" and 5 meant "Strongly Agree." The number 3 was considered a neutral response with no leaning in one directions or another. The instrument also had an open-question where the respondents were to list their 3 biggest concerns about growing old. The responses to this item were coded according to common descriptive responses and were analyzed using quantitative measures, as well as qualitative induction.

\subsection{Research Participants}

The study consisted of 154 respondents that reside in Southern California. The study employed a nonrandom sample of convenience. Respondents were recruited at various locations such as shopping malls, local colleges, and community businesses. There was no compensation given for filling out the questionnaire. Seeing that a primary goal of the study design was to have a diverse sample pool the only criterion for inclusion was that the respondents were willing to fill out the survey and that they needed to be at least 18 years of age or older. No minors were included in the study. The study included 98 women and 56 men. The age range of the respondents was from 18 to 72 . The bulk of respondents were in their 20 's $(63.6 \%)$, followed by respondents in their 30 's (12.3\%). Respondents in their 40 's and 50 's respectively made up $18.4 \%$ and $3.9 \%$ of the overall sample. There were 11 respondents aged 18 to 19 (7.1\%). Respondents over the age of 60 made up 4.5 percent of the sample. Hispanics made up the largest percentage of the respondents (42.2\%), followed by Whites (27.9\%), Black (9.1\%), Asian/Pacific Islander (8.4\%), Native American/Other (6.5\%). and Middle Eastern (5.8\%). These ethnic percentages are generally reflective of the greater Los Angeles area where the respondent reside.

\subsection{Data Analysis}

The data collected were computed and analyzed using the statistical software program SPSS 24. Descriptive statistics were employed across most analyses involving the categorical variables. The factor items in the questionnaire were analyzed for reliability using Cronbach's alpha and multiple statistical measures were taken for the general analysis. Pearson's correlations were used to detect any significant associations between key variables and scale items. The t-test for independent samples was used for analysis of gender responses and any meaningful statistical differences between these two groups. The one-way ANOVA was utilized to detect any significant differences between ethnic groups and clustered age groups. The level of statistical significance was set a 0.05 for all 
analyses. The direction of significance was generally two-tailed across most analyses.

The open-ended responses were categorized according to similarity of response and common themes (e.g., concerns with disease or illness, concerns about mental health, concerns with physical appearance). Responses were factored down to the most succinct number of categories that best reflected the range of common concerns and feelings described by the respondents. Any questionnaire item that was left blank was not included in any analysis pertaining to that specific item or category. All surveys appeared to be answered in a deliberate and honest manner and none had to be discarded for questionable or unclear responses.

\section{Study Results}

\subsection{Notable Descriptive Statistics}

When asked if we live in a society that respects the elderly $57.2 \%$ of the sample either disagreed with this (28.6\%) or were neutral about it (28.6\%). Only $13.6 \%$ of the sample agreed with this statement and $6.5 \%$ strongly agreed with it. The pattern in the responses leaned in the directions that society generally does not have a high amount of respect for the elderly $(\mathrm{M}=2.53, \mathrm{SD}=1.17)$. When respondents were asked if they generally had a positive attitude toward the elderly, $76 \%$ stated that they did, $\mathrm{M}=4.10, \mathrm{SD}=1.05$ ( $45.5 \%$ had very positive attitudes toward the elderly). When asked about their attitudes toward getting older $42.8 \%$ or the respondents were positive about it, $30.5 \%$ were neutral about it, and $26.6 \%$ had negative feelings about it $(\mathrm{M}=3.25, \mathrm{SD}=1.23)$. When asked if they had a fear of getting old the sample was split, with $37.6 \%$ stating that they did not fear getting old, $22.1 \%$ being neutral on the matter, and $40.2 \%$ having a self-reported fear of getting old. Females $(\mathrm{M}=3.17, \mathrm{SD}=1.44)$ reported having a slightly higher fear of aging than males $(\mathrm{M}=2.66, \mathrm{SD}=1.35)$. Respondents in their 50's $(\mathrm{M}=1.76, \mathrm{SD}=0.82)$ and 60 's $(\mathrm{M}=1.71, \mathrm{SD}=0.95)$ easily had the lowest levels of self-reported fear of getting old. Those under 40 had the highest levels of reported fear of getting old.

Almost half of the respondents (49.4\%) enjoy being around the elderly, while $19.5 \%$ do not. Thirty-nine percent of the respondents prefer being around younger people over older people, while $24 \%$ do not have this preference. With this said, $61.7 \%$ of the sample only associates with 3 elderly individuals on any kind of regular basis. Twenty-two of the respondents (14.3\%) stated that they never associate with any elderly individuals. When asked if getting older was "a big deal" for men, most men and women were somewhat neutral on this $(\mathrm{M}=$ $3.03, \mathrm{SD}=1.33)$. There was a slant toward disagreement when this same question was asked about women getting older $(\mathrm{M}=2.10, \mathrm{SD}=1.35)$. Respondents in their $40^{\prime}$ and $60^{\prime}$ 's seem to lean the furthest in this direction, with the most negative feelings about women getting old $(\mathrm{M}=1.85, \mathrm{SD}=0.81)$. In regard to getting older, Middle Eastern, Hispanic, and Black women seemed to have the 
most concerns about getting old $(\mathrm{M}=1.81, \mathrm{SD}=1.20)$. In regard to female respondents, Native Americans and women that identified as "Other" had the lowest concerns about getting old $(\mathrm{M}=2.90, \mathrm{SD}=1.60)$.

\subsection{Top Concerns about Growing Older}

The most common concern about growing older involved declining health/ physical pain ( $\mathrm{f}=30,19.5 \%)$. The second most frequent response involved declines in physical appearance $(\mathrm{f}=26.16 .9 \%)$. The third most common response revolved around the loss of independence and mobility $(\mathrm{f}=18,11.7 \%)$. In descending order, the other stated concerns revolved around death and dying $(\mathrm{f}=$ $17,11.0 \%)$, money/financial issues ( $f=16,104 \%)$, disease/illness ( $f=13,8.4 \%$ ), mental health/cognitive declines $(f=11,7.1 \%)$, death/health of loved ones $(f=$ $10,6.5 \%)$, being alone/isolated $(\mathrm{f}=10,6.5 \%)$, and disrespected/negative attitudes $(f=3,1.9 \%)$. Even though only $7.1 \%$ of the sample listed mental health/cognitive declines as their top concern, it was the listed as the second biggest concern more than any other concern listed. The top concern for the males involved declining physical health, whereas the top concern for the females involved declining physical appearance.

\subsection{Correlational Analysis}

A number of Pearson's correlations revealed significant associations between the variables of interest. Age was positively correlated with having a positive attitude toward the elderly $(\mathrm{r}=0.167, \mathrm{p}=0.039)$, regularly associating with the elderly $(\mathrm{r}=$ $0.321, \mathrm{p}=0.000)$, and enjoying being around the elderly $(\mathrm{r}=0.161, \mathrm{p}=0.047)$. Age was negatively correlated with a fear of getting old $(r=-0.213, p=0.008)$. Having a positive attitude about getting old was positively correlated with enjoying being around the elderly $(r=0.167, \mathrm{p}=0.039)$ and was negatively correlated with having a fear of getting old $(r=-0.510, \mathrm{p}=0.000)$. Having a positive attitude about the elderly was positively associated with enjoying being around the elderly $(\mathrm{r}=0.508, \mathrm{p}=0.000)$ and a negative association in regard to having a preference for being around younger people $(\mathrm{r}=-0.284, \mathrm{p}=0.000)$. Those that reported enjoying being around the elderly tend to not fear getting old ( $\mathrm{r}=$ $-0.204, \mathrm{p}=0.011$ ) and these individuals also revealed a significant negative association with having a preference for being around younger people $(r=-0.475$, $\mathrm{p}=0.000)$. Those that had a generally positive attitude toward the elderly felt that society generally does respect the elderly $(r=0.191, p=0.018)$. Those that reported a general preference for being around young people over old people also tend to have a fear of getting old $(\mathrm{r}=0.288, \mathrm{p}=0.000)$ and do not generally enjoy being around the elderly $(r=-0.475, \mathrm{p}=0.000)$. No significant correlations were found in regard to gender or ethnicity.

\subsection{Independent Samples $\mathrm{T}$}

An independent samples t-test was run to check for any notable differences be- 
tween the genders. After analyzing the difference between men and women it was found that men and women did not produce any significant differences in regard their attitudes toward the elderly, their feelings about being around the elderly, or having a preference for being around young over old people. A statistically significant finding was discovered in regard to the fear of aging. It would appear that women as a group generally have a stronger fear of getting old more than men do, $\mathrm{t}(152)=2.21, \mathrm{p}=0.029$.

\subsection{Analysis of Variance}

A one-way analysis of variance was run across age and ethnicity and various scale items. Younger respondents demonstrated a higher level of fear about getting old, $\mathrm{F}(5,148)=2.61, \mathrm{p}=0.027$, and are also less likely to associate with the elderly, $\mathrm{F}(5,148)=7.55, \mathrm{p}=0.000$. Younger respondents also feel that getting older for men is not a big deal, $\mathrm{F}(5,148)=2.95, \mathrm{p}=0.015$, but they did not feel the same way about women getting older. A check for any group differences in regard to ethnicity did not generally produce any significant results. For the most part, the different ethnic groups had similar views regarding the elderly, getting old, enjoying being around the elderly, and associating with the elderly. One noticeable difference did emerge in regard to ethnic differences and a preference for being around young people as opposed to older people, $\mathrm{F}(5,148)=$ $2.55, \mathrm{p}=0.031$. It would appear that Native Americans and Middle Eastern respondents do not favor associating with young people over older people.

\section{Discussion}

The present study set out to further explore general attitudes about aging and the elderly. Many prior studies have demonstrated that people often have a less than favorable attitude about growing old [5] [6] [18] [22] and about the elderly in general [7] [11] [12] [19]. Other studies have shown that most people tend to have mixed feelings about the elderly (e.g., that they are both warm and incompetent) [3] [14] [17]. The results of this study have largely supported what has been presented in prior research. Most of the respondents had somewhat ambivalent feelings about getting older and about the elderly in general. Many of the respondents expressed a somewhat neutral stance on the elderly, but they still tended to express concerns about getting older themselves. This was a common finding in this study and applies to the majority of the respondents.

There has also been a solid amount of data that supports the notion that younger people tend to have more negative feelings about the elderly [6] [12] [16] [19] and that there is an increased biased against older women [6] [20] [21]. This study did show that women do tend to have a greater fear of aging than men. This is something that could be directly connected to historical and cultural factors that have long placed a greater emphasis on female beauty and appearance. It would only make sense that women would be more concerned about losing their looks as they age if this is what they have been taught by society 
since the day they were born. All one has to do is look at the media (e.g., TV, film, fashion magazines) and it is clear that there is premium placed on youth and beauty. The same could be said about men to some extent but it does not nearly reach the same level of cultural and interpersonal pressure that we see with females. Many researchers and social theorists have placed much of the blame on this with the mass media and its focus on external appearances and youth [2] [7] [8] [22].

The findings of this study seem to support these basic gender differences. Although the women in this study did not show a higher level of negativity toward the elderly, they did demonstrate a higher level of fear in regard to growing old themselves. This was further supported with the finding that the number one concern that the women have about getting older is declining physical appearance. For the men, the number one concern involves declines in physical health. When women were asked about men and growing old they tended to respond that it was not that big of a deal. When the men were asked about women growing old they tended to have a more negative attitude about it. This also fits in with the aging bias that we see across the media and across society in general. Men often seem to gain more status as they age. Women often seem to lose status as they age. This does not apply to all men and women of course, but the general cultural patterns are pretty clear.

The younger respondents in this study also showed a higher level of bias and negativity toward the elderly. It would appear that the younger people are the less likely they are to associate with the elderly and the more likely they are to hold certain stereotypic attitudes toward them. These findings were supported by statistically significant results in regard to correlational analysis of the relevant variables (e.g., age and fear of getting old) and multiple analysis of variance interpretations. These findings have been noted in other studies looking at prejudice and stereotypes of the elderly and some common themes do seem to emerge, such as the elderly often being perceived as being frail, senile, incompetent, unproductive, and burdens on society [4] [9] [18]. It would appear that we also live in society that values youth over old age. This is another type of bias that we can commonly see in the media and how old age is commonly depicted. As long as the mass media continue to promote the perception that youth is beautiful and good, and that being old is unattractive and undesirable, we can only expect to see these types of negative attitudes and prejudicial stereotypes to continue.

It was interesting to see that there were no real differences between ethnic groups in this study. It would appear that the major differences noted between groups had more to do with age and gender than ethnicity. There were some notable things that stood out during data analysis. For example, Black women seem to have the most positive attitudes about older women. This would make sense because it is believed that Black women do not subscribe to larger cultural depictions and stereotypes about youth and beauty as much as White and His- 
panic women. The data also revealed that Native American and Middle Eastern respondents had the most favorable attitudes about being around the elderly. These findings would make sense when one looks at historical and cultural norms and values across these groups. Native Americans have long held the elderly is high regard and older tribal members are often afforded the highest status and respect. With this being the case historically, there also seems to be some changes among these groups that could be tied to larger social changes, materialism, and living in postindustrial society [16] [23].

As an increasing number of people become even more acculturated to postmodern lifestyles and belief systems it will become even more important to pay attention to any changing attitudes and feelings about the elderly. These attitudinal and behavioral changes could have a serious negative impact on the lives and functioning of our society's senior members (e.g., elder abuse, neglect, harmful policy changes). We must work hard to ensure that society's eldest members are treated with the respect and dignity that they deserve. As the world's population continues to age it will be imperative that we give further attention to this important social issue.

\subsection{Limitations}

This study was designed for quantitative analysis and interpretation. This study did not probe further in the reasoning and perceptions of the respondents. It is difficult to know exactly why the respondents felt the ways that they did about aging and the elderly. This is something that would need to be addressed in a more qualitative design where more unstructured questioning and probing of responses could take place. The respondents of the study were also from the Southern California area. There may be differences in attitudes and feelings with those from other parts of the country (e.g., the South or the Mid-Western states). It would also be helpful to put together research that focused more on discrete age groups. The respondents in this study ranged from 18 into their early 70 's. In fact, $91.6 \%$ of the respondents were under the age of 50 . Only 13 respondents were over the age of 50. It would be helpful to have a sizable sample of respondents 70 and older to get a better sense of how the eldest members of society feel about aging and growing old.

\subsection{Contributions and Directions for Future Research}

This study has added further support to the existing literature regarding ageism and general attitudes toward the elderly. This study has further highlighted a prevailing problem that we are seeing across the nation. American society is generally an ageist society that devalues the elderly and stigmatizes them in numerous ways. This study has further illuminated the prevailing fear that most people have about getting older and about how many people feel about the elderly. An important finding in this study was that most people have somewhat ambivalent feelings and attitudes about the elderly. These findings can be con- 
nected to larger social forces and institutions, such as the mass media. An important contribution of this study is that there appears to be a decreasing fear about old age the older people get. Even though older people tend to have mixed feelings about being old, they do not have the same level of fear about aging and getting old. The study also brings forth some important group differences that could be explored further in future studies, such as gender and ethnic differences and fear about growing old and about attitudes toward the elderly in general. All of this has real implications on tens of millions of American lives. Ageism and prejudice toward the elderly affects bit their mental and physical health. Studies such as this help to bring forth the need for further research in this area, as well as for increased applied interventions.

As the mass media continues to become more integrated into people's daily lives it will be essential that researchers pay close attention to how this will affect the lives of the elderly. The mass media has a clear bias when it comes to age and what is considered valuable and important. The elderly are often ignored in movies and television. The elderly are completely absent from the covers of fashion and beauty magazines. Future research will need to focus on how larger social institutions are influencing how the elderly are being treated. Future research will also need to focus more on how social institutions are shaping how each new generation perceives and feels about aging and the elderly. The most important social institutions in this regard involve the mass media, education, and government. Attitudes and beliefs are heavily influence and shaped by all three of these institutions. The family is also at the core of this social issue. Researchers will need to further investigate how the values and attitudes of parents are shaping the values and attitudes (and behaviors) of their children. There is much more research needed in these important areas to help ensure that we can improve the lives and functioning of the elderly.

\section{Conclusion}

The elderly population in the United States and around the world is going to continue to grow over time. In fact, the elderly population is the fastest growing segment of the population in America, as well as in many other nations around the world. As the overall numbers of the elderly grows it will be even more important to pay close attention to how society views them and feels about them. Negative attitudes and perceptions have a real impact on people's lives. The elderly are harmed in many different ways when they are viewed negatively. We must remain diligent and work very hard to ensure that our eldest members of society are always treated with the dignity and respect that they deserve.

\section{References}

[1] Robinson, S. and Howatson-Jones, L. (2014) Children's Views of Older People. Journal of Research in Childhood Education, 28, 293-312. https://doi.org/10.1080/02568543.2014.912995

[2] Berger, R. (2009) Celebrity Court Cases: The Psychology of Why We Watch. Arm- 
bar, Los Angeles.

[3] Cuddy, A.J., Norton, M.I. and Fiske, S.T. (2005) This Old Stereotype: The Pervasiveness and Persistence of the Elderly Stereotype. Journal of Social Issues, 61, $267-$ 285. https://doi.org/10.1111/j.1540-4560.2005.00405.x

[4] Blakeborough, D. (2008) “Old People Are Useless": Representations of Aging on the Simpsons. Canadian Journal on Aging, 27, 57-67. https://doi.org/10.3138/cja.27.1.57

[5] Nelson, T.D. (2005) Ageism: Prejudice against Our Feared Future Self. Journal of Social Issues, 61, 207-221. https://doi.org/10.1111/j.1540-4560.2005.00402.x

[6] Kimmel, D.C. (1988) Ageism, Psychology, and Public Policy. American Psychologist, 43, 75-178. https://doi.org/10.1037/0003-066X.43.3.175

[7] Thornton, J.E. (2002) Myths of Aging or Ageist Stereotypes. Educational Gerontology, 28, 301-312. https://doi.org/10.1080/036012702753590415

[8] Haboush, A., Warren, C.S. and Benuto, L. (2011) Beauty, Ethnicity, and Age: Does Internalization of Mainstream Media Ideals Influence Attitudes toward Older Adults? Sex Roles, 66, 668-676. https://doi.org/10.1007/s11199-011-0102-6

[9] Kessler, E., Rakoczy, K. and Staudinger, U.R. (2004) The Portrayal of Older People in Prime Time Television Series: The Match with Gerontological Evidence. Ageing and Society, 24, 531-552. https://doi.org/10.1017/S0144686X04002338

[10] Lin, X. and Bryant, C. (2009) Students' Attitudes toward Older People: A CrossCultural Comparison. Journal of Intergenerational Relationships, 7, 411-424. https://doi.org/10.1080/15350770903285320

[11] McKenzie, E.L. and Brown, P.M. (2014) Nursing Students' Intentions to Work in Dementia Care: Influence of Age, Ageism, and Perceived Barriers. Educational Gerontology, 40, 618-633. https://doi.org/10.1080/03601277.2013.863545

[12] Bodnar, E. and Lazar, A. (2008) Ageism among Israeli Students: Structure and Demographic Influences. International Psychogeriatrics, 20, 1046-1058. https://doi.org/10.1017/S1041610208007151

[13] Vauclair, C., Hanke, K. and Abrams, D. (2017) Are Asians Cultures Really Less Ageist That Western Ones? It Depends on the Questions Asked. International Journal of Psychology, 52, 136-144. https://doi.org/10.1002/ijop.12292

[14] Sharps, M.J., Price-Sharps, J.L. and Hanson, J. (1998) Attitudes of Younger Adults toward Older Adults: Evidence from the United States and Thailand. Educational Gerontology, 24, 655-660. https://doi.org/10.1080/0360127980240703

[15] Luo, B., Zhou, K., Jin, E., Newman, A. and Liang, J. (2013) Ageism among College Students: A Comparative Study between U.S. and China. Journal of Cross Cultural Gerontology, 28, 49-63. https://doi.org/10.1007/s10823-013-9186-5

[16] Lagace, M., Charmarkeh, H. and Grandena, F. (2012) Cultural Perceptions of Aging: The Perspective of Somali Canadians in Ottawa. Journal of Cross Cultural Gerontology, 27, 409-424. https://doi.org/10.1007/s10823-012-9180-3

[17] Zhang, X., Xing, C., Guan, Y., Song, X., Melloy, R. and Wang, F. (2016) Attitudes toward Older Adults: A Matter of Cultural Values or Personal Values? Psychology and Aging, 31, 89-100. https://doi.org/10.1037/pag0000068

[18] North, M.S. and Fiske, S.T. (2015) Modern Attitudes toward Older Adults in the Aging World: A Cross-Cultural Meta-Analysis. Psychological Bulletin, 141, $993-$ 1021. https://doi.org/10.1037/a0039469

[19] Ward, R. and Holland, C. (2011) If I Look Old I Will Be Treated Old: Hair and Later-Life Image Dilemmas. Ageing and Society, 31, 288-307.

https://doi.org/10.1017/S0144686X10000863 
[20] Allen, K.R. and Roberto, K.A. (2009) From Sexism to Sexy: Challenging Young Adults' Ageism about Older Women's Sexuality. Sexuality Research and Social Policy, 6, 13-24. https://doi.org/10.1525/srsp.2009.6.4.13

[21] Thompson, E.H. (2006) Images of Old Men's Masculinity: Still a Man? Sex Roles, 55, 633-648. https://doi.org/10.1007/s11199-006-9119-7

[22] Robinson, T., Gustafson, B. and Popovich, M. (2008) Perceptions of Negative Stereotypes of Older People in Magazine Advertisements: Comparing the Perceptions of Older Adults and College Students. Ageing and Society, 28, 233-251. https://doi.org/10.1017/S0144686X07006605

[23] Anisko, B. (2009) Elder Abuse in American Indian Communities. American Indian Culture and Research Journal, 33, 43-51.

https://doi.org/10.17953/aicr.33.3.b455qt1714213883 


\section{Appendix}

\section{Study Questionnaire}

Circle each appropriate response: For the purposes of this questionnaire the aging (elderly) population refers to anyone 65 years of age and older.

-Gender: Woman Man

-Age:

-Which ethnic group do you most identify with:

-Getting older for men is not a big deal:

$\begin{array}{llllllll}\text { Strongly disagree } & 1 & 2 & 3 & 4 & 5 & \text { Strongly agree }\end{array}$

- Getting older for women is not a big deal:

$\begin{array}{llllllll}\text { Strongly disagree } & 1 & 2 & 3 & 4 & 5 & \text { Strongly agree }\end{array}$

-I Generally have a positive attitude about aging (getting older):

$\begin{array}{llllllll}\text { Strongly disagree } & 1 & 2 & 3 & 4 & 5 & \text { Strongly agree }\end{array}$

-I generally have a positive attitude toward the elderly:

$\begin{array}{llllllll}\text { Strongly disagree } & 1 & 2 & 3 & 4 & 5 & \text { Strongly agree }\end{array}$

-I have a fear of getting old:

$\begin{array}{llllllll}\text { Strongly disagree } & 1 & 2 & 3 & 4 & 5 & \text { Strongly agree }\end{array}$

-I enjoy being around elderly adults:

$\begin{array}{llllllll}\text { Strongly disagree } & 1 & 2 & 3 & 4 & 5 & \text { Strongly agree }\end{array}$

-We live in a society that respects the elderly:

$\begin{array}{llllllll}\text { Strongly disagree } & 1 & 2 & 3 & 4 & 5 & \text { Strongly agree }\end{array}$

-I prefer being around young people rather than old people:

$\begin{array}{llllllll}\text { Strongly disagree } & 1 & 2 & 3 & 4 & 5 & \text { Strongly agree }\end{array}$

-How many people aged 65 and older do you regularly associate with?

Write down the top three things that concern you the most about growing old:

$$
\begin{aligned}
& 1 \\
& 2 \\
& 3
\end{aligned}
$$

Submit or recommend next manuscript to SCIRP and we will provide best service for you:

Accepting pre-submission inquiries through Email, Facebook, LinkedIn, Twitter, etc.

A wide selection of journals (inclusive of 9 subjects, more than 200 journals)

Providing 24-hour high-quality service

User-friendly online submission system

Fair and swift peer-review system

Efficient typesetting and proofreading procedure

Display of the result of downloads and visits, as well as the number of cited articles

Maximum dissemination of your research work

Submit your manuscript at: http://papersubmission.scirp.org/

Or contact jss@scirp.org 